\title{
openheart Magnesium for the prevention and treatment of cardiovascular disease
}

\author{
James J DiNicolantonio, ${ }^{1}$ Jing Liu, ${ }^{2}$ James H O’Keefe ${ }^{1}$
}

To cite: DiNicolantonio JJ, Liu J, O'Keefe JH. Magnesium for the prevention and treatment of cardiovascular disease. Open Heart 2018;5:e000775. doi:10.1136/ openhrt-2018-000775

Accepted 1 May 2018

Check for updates

${ }^{1}$ Department of Preventive Cardiology, Saint Lukes Mid America Heart Institute, Kansas City, Missouri, USA

${ }^{2}$ Department of Internal Medicine, Baylor College of Medicine, Houston, Texas, USA

Correspondence to Dr James J DiNicolantonio; jjdinicol@gmail.com

\section{INTRODUCTION}

Magnesium is an essential mineral found in the body. It is naturally present in many foods and is also available as a dietary supplement. ${ }^{1}$ It serves as a cofactor in more than 300 enzymatic reactions, such as those responsible for regulating blood pressure, glycaemic control and lipid peroxidation. It is therefore also critical to the cardiovascular system. ${ }^{1}$ The adult body contains approximately $24 \mathrm{~g}$ of magnesium, with $50 \%$ to $60 \%$ present in bones with the rest being contained in soft tissues. Serum magnesium represents less than $1 \%$ of total body magnesium. ${ }^{2}$ In industrialised western countries, a low intake of magnesium often predisposes to a high prevalence of magnesium deficiency increasing the risk of cardiovascular events and cardiovascular death. ${ }^{3}$ This article aims to review of effect of magnesium deficiency on the cardiovascular system.

\section{BIOCHEMICAL INTERACTIONS OF MAGNESIUM IN CARDIOVASCULAR DISEASES}

In recent studies of hospitalised patients, $42 \%$ were shown to be hypomagnesaemic. ${ }^{4}$ However, physicians request magnesium testing in only $7 \%$ of these patients. ${ }^{4}$ In a study conducted among patients in the intensive cardiac care unit, $53 \%$ of patients had mononuclear cell magnesium content below the lowest normal control. ${ }^{5}$

Clinically, serum magnesium is usually measured despite the fact that less than $1 \%$ of magnesium exists extracellularly; hence, serum magnesium does not always accurately reflect total body magnesium stores. In fact, serum magnesium levels may be normal despite depletion of total body magnesium content. ${ }^{5}$ In experimental settings, total body magnesium stores can be estimated by measuring retention of an oral or intravenous magnesium load; however, measurement is cumbersome and requires a 24-hour urine collection. ${ }^{67}$ In many instances, intracellular levels of magnesium serve as a better indicator for total body magnesium content compared with serum magnesium levels with the most accurate test being blood mononuclear cell magnesium. ${ }^{8}$ Intracellular mononuclear magnesium content also correlates better with cardiac magnesium status. ${ }^{9-12}$

Magnesium plays diverse roles in the pathogenesis of cardiovascular diseases on the biochemical and cellular levels. First, magnesium activates adenosine triphosphatase (ATPase), which is essential for cell membrane functioning and is also the energy source of the Na+-K+ pump. ${ }^{13}$ In rat models, magnesium deficiency has been shown to decrease the activity of the Na+-K+ pump, leading to an increase in intracellular sodium, which alters the membrane potential. ${ }^{14}$ In studying the sodium kinetic and membrane potential in the aorta of magnesium-deficient rats, Madden et al also showed that magnesium deficiency caused the membrane potential to be less polarised as a result of intracellular sodium accumulation, suggesting Na+-K+pumpinhibition. ${ }^{15}$ This change in membrane potential has been hypothesised as a potential mechanism for causing arrhythmias. Magnesium is also known to be a cofactor important for the functioning of the enzymes in cardiac mitochondria. Additionally, magnesium has been demonstrated to modulate the potassium-proton exchange. Cation selectivity in sodium and potassium exchange for protons is highly dependent on magnesium. Thus, magnesium also protects against potassium loss. Intracellular magnesium deficiency may also cause an increase in intracellular sodium and calcium, which predisposes to arterial vasospasm, increased catecholamine release, increased fatty acids and lipids, as well as intravascular hypercoagulability. ${ }^{13} 16$

Furthermore, magnesium deficiency has been shown to play a role in inflammation in the rat model. Weglicki et al showed that during progression of magnesium deficiency, there is an increase in the serum levels of 
inflammatory cytokines interleukin-1, interluein-6 and tumour necrosis factor after 3 weeks of magnesium-deficiency diet. ${ }^{17}$ Magnesium deficiency also leads to an exaggerated response to immune stress and oxidative stress through activation of neuroendocrinological pathways. This inflammatory response predisposes to proatherogenic changes in lipoprotein metabolism, endothelial dysfunction, thrombosis and hypertension, contributing to the pathogenesis of metabolic syndrome as well as cardiovascular diseases. ${ }^{3}$

\section{EPIDEMIOLOGY}

Despite the importance of magnesium for the proper functioning of the cardiovascular system, surveys and studies have shown that dietary magnesium intake is often inadequate in the USA, which is consistent with the pattern observed in North European countries. Several factors were thought to be contributory, including the loss of magnesium during food processing, low magnesium content of vegetarian diets, metabolic effects exerted by pregnancy, osteoporosis medication therapy, alcoholism, stress, as well as the differing magnesium content in water. ${ }^{18}$ Human dietary requirement for essential minerals such as magnesium is not precisely known. Based on earlier balance studies, recommended dietary magnesium intakes were 300 to $354 \mathrm{mg}$ /day for American women and 420 to $483 \mathrm{mg} /$ day for American men. ${ }^{19}$ However, other studies have indicated that around $180 \mathrm{mg}$ of magnesium per day may be enough to maintain positive magnesium balance. ${ }^{8}$ Actual intakes in American women and men are approximately $228 \mathrm{mg}$ / day and $331 \mathrm{mg} /$ day, respectively. ${ }^{19}$

Interestingly, there may be an association between cardiovascular disease and drinking water hardness due to its differing magnesium content. A study by Catling $e t$ al systematically reviewed observational epidemiological studies investigating the association between levels of drinking water hardness and cardiovascular disease. Of the seven studies included that examined drinking water magnesium and risk of death from cardiovascular disease, a pooled OR of 0.75 (95\% CI 0.68 to 0.82 ) showed a statistically significant inverse correlation between magnesium and cardiovascular mortality. ${ }^{20}$ Additionally, changes in water hardness and a change to soft water tended to predispose to increased death rates from cardiovascular diseases including heart attacks and strokes. ${ }^{21}$ Autopsies of patients in soft-water areas who died from non-cardiac causes were found to have lower levels of magnesium in cardiac tissues, more coronary atheroma and evidence of myocardial ischaemia compared with residents living in hard water areas. ${ }^{2122}$ However, the results of these studies may be confounded by the presence of many other trace elements found in hard water, such as calcium, which have also been found to have beneficial effects in preventing cardiovascular diseases. The magnesium content also differed among the hard waters in the studies, representing another confounding factor. Other studies have found no difference in cardiovascular disease morbidity and mortality in hard-water versus soft-water regions. ${ }^{23-27}$

\section{HYPERTENSION}

Hypertension is a complex, multifactorial, heterogeneous disorder for which the exact aetiology has yet to be elucidated. Clinical and experimental trials have suggested that magnesium may play a role in the pathogenesis of hypertension by affecting arterial smooth muscle contraction. Magnesium is found mainly at the inner surface of cell membranes. Therefore, it plays a role in cell membrane permeability for sodium and calcium. ${ }^{28}$ Magnesium activates the $\mathrm{Na}+-\mathrm{K}+-\mathrm{ATPase}$ pump, which plays a major role in regulating sodium and potassium transport by moving potassium into the cells and sodium out of the cells. Alterations in vascular membrane magnesium can also result in leaky arterial and arteriolar membranes, thus contributing to the intracellular reduction of potassium and the gain of calcium and sodium. Increased intracellular calcium can then lead to hypertension, vasospasm, as well as potentiation of vasoconstrictor agents. ${ }^{29}$

A number of observational and experimental studies have supported the role of magnesium depletion in the pathogenesis of hypertension. Hypertension has been shown to develop in magnesium-deficient rats. ${ }^{30}$ In humans, a similar effect of magnesium deficiency was observed. A study by Shibutani et al studying a group of 380 Japanese junior high school students found that higher systolic blood pressure was associated with positive family history of hypertension as well as lower serum and erythrocyte magnesium levels, suggesting that magnesium deficiency may at least be partially responsible for a rise in blood pressure in the students with positive family history of hypertension, and that a genetic predisposition of hypertension maybe closely related to magnesium deficiency. ${ }^{31}$

Multiple studies have analysed the effect of magnesium supplementation on blood pressure. The effect of water with added magnesium and natural mineral water on blood pressure have been studied by dividing a group of 70 subjects with borderline hypertension into consuming water low in minerals, magnesium-enriched water and natural mineral water for 4 weeks. Among persons with initial low excretion of magnesium (suggesting magnesium deficiency), the subjects consuming the two waters containing magnesium after 4 weeks had a significant decrease in blood pressure. ${ }^{32}$ In a meta-analysis conducted by Zhang et al including randomised doubleblind placebo control trials, magnesium supplementation at a median dose of $368 \mathrm{mg} /$ day for a median duration of 3 months was found to significantly reduce systolic blood pressure (SBP) by $2.00 \mathrm{~mm} \mathrm{Hg}$ (95\% CI 0.43 to 3.58 ) and diastolic BP (DBP) by $1.78 \mathrm{~mm} \mathrm{Hg}(95 \%$ CI 0.73 to 2.82 ). Additionally, these reductions were accompanied by $0.05 \mathrm{mmol} / \mathrm{L}(95 \%$ CI 0.03 to 0.07 ) elevation of serum magnesium compared with placebo. ${ }^{33}$ Similarly, Kass et al also found that magnesium supplementation leads to a 
small but clinically significant reduction in both DBP and SBP (SBP of 3 to $4 \mathrm{~mm} \mathrm{Hg}$ and DBP of 2 to $3 \mathrm{~mm} \mathrm{Hg}$ ). ${ }^{34}$ These studies suggest that magnesium supplementation may be beneficial for lowering blood pressure in certain patient populations.

The effect of magnesium supplementation on patients taking diuretics has been studied in several trials. Hattori et al looked at 20 patients with essential hypertension receiving long-term thiazide diuretic treatment and 21 age-matched untreated patients. The diuretic group received magnesium supplementation for 4 weeks. There were significant decreases in intra-erythrocyte sodium content and mean blood pressure, as well as increases in red cell magnesium content in the diuretic group who received magnesium supplementation. The effect of magnesium on blood pressure reduction was more evident in the nine patients who were unresponsive to diuretic therapy. ${ }^{35}$ In a meta-analysis involving 135 hypertensive subjects on antihypertensive medications, Rosanoff and Plesset found that oral magnesium supplementation decreases both systolic (mean change of $-18.7 \mathrm{~mm} \mathrm{Hg}$ (95\% CI -14.95 to -22.45$)$ ) and diastolic blood pressures $(-10.9 \mathrm{~mm} \mathrm{Hg}(95 \% \mathrm{CI}-8.73$ to -13.1$)){ }^{36}$

\section{CARDIOMYOPATHY}

Magnesium deficiency has been implicated in the cause of cardiomyopathy in both animal models and studies involving humans. In animal models, hamsters fed a magnesium-deficient diet developed a cardiomyopathy with foci of myocardial necrosis, calcification and modest mononuclear and giant cell infiltration. Additionally, hamsters given nifedipine had a dose-dependent reduction in lesion abundance and diameter, while hamsters given digoxin produced a dose-dependent increase in lesion abundance and diameter. These results support the hypothesis that the lesions are secondary to calcium overload following an increase in myocardial sodium due to inhibition of the Na+-K+-ATPase and secondary sodium, calcium exchange in a magnesium-deficient state ${ }^{37}$ In a different study involving Syrian male hamsters fed either a magnesium-deficient diet or identical diet supplemented with $100 \mathrm{mmol} / \mathrm{kg}$ of $\mathrm{MgCl}$, animals were found more vulnerable to ischaemia-induced damage to the heart when magnesium deficient at the time the animals were sacrificed. ${ }^{38}$ The release and effects of catecholamines have been shown to intensify during cellular magnesium depletion. The detrimental effect of catecholamine excess and magnesium deficiency has been found to be synergistic in the myocardium. In rabbits, magnesium supplementation has been found to reduce the ultrastructural features of myocardial damage induced by epinephrine injection without an effect on changes in intracellular distribution of calcium induced by epinephrine. ${ }^{39}$

In humans, studies also support the role of magnesium in cardiomyopathy. Patients with hypoparathyroidism can manifest cardiomyopathy, which responds to magnesium supplementation. ${ }^{40}$ Cardiomyopathy and magnesium deficiency are commonly observed in patients with heavy alcohol consumption. ${ }^{41}$ Additionally, people who live in low magnesium equatorial areas, and those consuming a magnesium-deficient diet, have developed spontaneous endomyocardial fibrosis of undetermined aetiology. ${ }^{41-43}$

\section{CONGESTIVE HEART FAILURE}

Magnesium deficiency is commonly found in patients with congestive heart failure due to various mechanisms. Patients with congestive heart failure may have an increased urinary excretion of magnesium, secondary to decreased tubular absorption of magnesium as a result of increased extracellular volume and the effects of secondary hyperaldosteronism found in heart failure. Medications, such as diuretics and digoxin, can also worsen the problem and decrease tubular reabsorption of magnesium. Hyperactive renin-angiotensin system may further elevate aldosterone levels in the body, further exacerbating a state of magnesium deficiency. Additionally, norepinephrine in a state of heart failure has been shown to reduce magnesium through increased fatty acids. ${ }^{44-52}$ Adding to the vicious cycle, magnesium deficiency may worsen hyperaldosteronism, which may lead to fluid retention.

In patients with heart failure, hypomagnesaemia also predisposes to hypokalaemia, therefore increasing the chance of developing ventricular arrhythmias and haemodynamic derangements. Finally, magnesium depletion may worsen cardiac contractility, increase vasoconstriction and deplete cardiac energy stores. ${ }^{53}$ Magnesium deficiency has even been shown to worsen clinical outcomes in patients with congestive heart failure. Micronutrient deficiency is found to be independently predictive of poor health-related quality of life (HRQoL) and shorten cardiac event-free survival in patients with heart failure. ${ }^{54}$ Storm and Zimmerman reported a case of cardiogenic shock developing after cardiopulmonary bypass that was initially unresponsive to therapeutic intervention, which resolved promptly after magnesium administration. ${ }^{55}$ Gottlieb et al found that patients with normal versus low magnesium levels had 2-year survival rates of $61 \%$ and $42 \%$, respectively. It was hypothesised that hypomagnesaemia lead to deaths due to ventricular arrhythmias. ${ }^{56}$

Because electrolyte abnormalities are a frequent and potentially hazardous complication in patients with heart failure, magnesium likely improves outcomes in patients with congestive heart failure by preventing ventricular arrhythmias. Bashir et al investigated the effect of oral magnesium supplementation in a randomised, double-blind, cross-over trial involving 21 patients with stable congestive heart failure secondary to coronary artery disease and who were receiving long-term loop diuretics. Oral magnesium supplementation was found to lower mean arterial pressure, systolic vascular resistance and the frequency of isolated ventricular premature complexes, couplets and non-sustained ventricular 
tachyarrhythmia. ${ }^{57}$ However, more studies are needed to establish whether routine supplementation of magnesium in patients with heart failure is warranted. In fact, Ralston et al showed that the prevalence of hypomagnesaemia in ambulatory patients with dilated cardiomyopathy is relatively low (9\%); however, magnesium is 99\% intracellular and hence there is a poor correlation between serum, mononuclear cells, skeletal muscles cells and cardiac muscle cell magnesium levels. ${ }^{58}$

\section{CARDIAC ARRHYTHMIA}

The importance of magnesium supplementation in preventing arrhythmias in patients with congestive heart failure has long been established. Magnesium deficiency can lead to QT interval prolongation, ST-segment depression and low amplitude $\mathrm{T}$ waves. ${ }^{59-61}$ Magnesium also influences the movement of other ions such as potassium, sodium and calcium across the cell membranes. The association between magnesium and potassium is probably best demonstrated in that magnesium deficiency is often accompanied by potassium deficiency. In patients with congestive heart failure, both magnesium and potassium are depleted with thiazide diuretics, particularly in patients requiring high doses of thiazide diuretics. ${ }^{62-65}$ It has been shown that the level of potassium in muscle will not normalise unless magnesium is replaced, even though serum potassium rises with repletion. ${ }^{62} 6667$ The ominous role of magnesium depletion in predisposing to arrhythmias in patients with congestive heart failure is perhaps best demonstrated in a recent prospective study showing that among the $66 \%$ of patients with cardiac arrest who had magnesium abnormalities, none were successfully resuscitated. ${ }^{68}$

\section{SUPRAVENTRICULAR TACHYCARDIA}

A large percentage of patients with supraventricular arrhythmias have an intracellular magnesium deficiency despite having normal serum magnesium concentrations, and this may explain the rationale for magnesium's benefits as an atrial antiarrhythmic agent. ${ }^{69}$ Magnesium enhances atrial antiarrhythmic efficacy when used as monotherapy ${ }^{69}$ Maurat et al found that in vitro, changes in atrial action potential can be induced experimentally by a fall in extracellular potassium or by digoxin overdose. Increasing magnesium concentration in the medium can correct these changes in atrial action potential. Magnesium does not seem to act on the Na+-K+-ATPase activity but rather exert its effect through moderating the calcium inflow into the cell, which is favoured by hypomagnesaemia. ${ }^{70}$ In the Framingham Heart Study, individuals in the lowest quartile of serum magnesium were $50 \%$ more likely to develop atrial fibrillation compared with those in the upper quartiles. Results were similar after the exclusion of individuals on diuretics. As a result, low serum magnesium is moderately associated with development of atrial fibrillation in individuals without cardiovascular disease. ${ }^{71}$ To make matters worse, hypomagnesaemia is common among patients with symptomatic atrial fibrillation, ${ }^{72}$ and replacement of magnesium deficiency may be beneficial in patients with symptomatic atrial fibrillation who are receiving digoxin therapy. Similarly, a study by Lewis $e$ al suggested that treatment with magnesium may be associated with a decreased prevalence of ventricular ectopy in some patients receiving digoxin with chronic atrial fibrillation and mild-moderate hypomagnesaemia. ${ }^{73}$

However, not all studies find a clinically significant association between hypomagnesaemia and improved outcomes in atrial fibrillation. Eray et al assessed the effect of magnesium supplementation on lowering the rate in patients with atrial fibrillation with rapid ventricular response and evaluated the effect of this therapy in magnesium-deficient and non-deficient patients. The decrease in the ventricular rate was statistically significant at 15, 30 and $60 \mathrm{~min}$ after magnesium therapy; however, there was no difference in the response to magnesium between magnesium-deficient and non-deficient patients. The authors concluded that magnesium supplementation had a statistically significant but clinically limited effect on ventricular rate and its effect did not differ between patients with and without magnesium deficiency. $^{74}$

In addition to atrial fibrillation, the effect of hypomagnesaemia has also been studied in other forms of supraventricular dysrhythmias. Cohen et al studied two groups of patients with multifocal atrial tachycardia treated with intramuscular and continuous intravenous magnesium and found that both routes of administration were successful in reverting patients back to sinus rhythm. However, the intramuscular regimen attains higher and more sustained serum concentrations. ${ }^{75}$ In a separate study, seven patients with congestive heart failure receiving long-term diuretics as well as digoxin experienced idional tachycardia. Intravenous administration of magnesium followed by intramuscular magnesium repletion was noted to abolish the arrhythmias. Interestingly, decreased lymphocyte magnesium and potassium content but normal serum magnesium levels were found in five patients, again suggesting that normal serum magnesium does not preclude total body magnesium deficiency, and a decreased cellular magnesium level predisposes to digitalis-induced arrhythmias. ${ }^{76}$

\section{VENTRICULAR ARRHYTHMIA}

Magnesium therapy has also been shown to be effective in patients with ventricular tachycardia. Magnesium supplementation may be a viable therapeutic option when other antiarrhythmic agents fail to suppress ventricular tachycardia and ventricular fibrillation. ${ }^{77}$ In animal models, magnesium-deficient dogs showed increased pressor sensitivity to epinephrine as determined by the dose of epinephrine required to cause a maximum pressor response. Magnesium-deficient dogs also had a significantly lower threshold for triggering 
ventricular premature beats. Administration of magnesium in these dogs restored the pressor sensitivity level and abolished premature ventricular beats. ${ }^{78}$ In humans, a significant increase in cellular potassium content and likewise a significant decrease in frequency of ventricular ectopic beats were noted after magnesium infusions. ${ }^{63}$ Magnesium may be exerting its antiarrhythmic effects by preventing prolonged QTc. Krasner et al studied 24 patients scheduled electively for mitral valve replacement and found that all patients who developed arrhythmias postoperatively had not been pretreated with oral magnesium and had abnormal QTc intervals both before and after operation. ${ }^{79}$

The role of intravenous magnesium supplementation has also been studied in patients with acute myocardial infarction who received thrombolytic therapy. Ventricular arrhythmias were less in the experimental group supplemented with magnesium, suggesting that magnesium supplementation may be a safe and effective adjuvant to thrombolytic therapy in reducing the short-term mortality and ventricular arrhythmias after acute myocardial infarction. ${ }^{80}$ Magnesium depletion has long been associated with severe ventricular arrhythmias such as torsades de pointes. Papaceit et al reported a case of a patient with chronic magnesium depletion who developed torsades de pointes and had good response to magnesium supplementation. ${ }^{81}$ However, magnesium supplementation has not been shown to reduce implantable cardioverter-defibrillator (ICD) firing rates. The trial, however, was underpowered. More prospective, large, randomised controlled trials are needed to further elucidate the effect of magnesium supplementation on ventricular arrhythmias in ICD patients.

\section{SUDDEN CARDIAC DEATH}

A link between magnesium deficiency and sudden cardiac death has been suggested by a number of studies published over the past few decades. Data from epidemiological, autopsy, clinical and animal studies suggest that sudden cardiac death is more common in areas where community water supplies are low in magnesium content. Additionally, myocardial magnesium content is found to be low in patients who died of sudden cardiac death. Sudden cardiac death secondary to magnesium deficiency may be secondary to cardiac arrhythmias and coronary artery vasospasm. Finally, repletion of magnesium has been found to reduce the risk of arrhythmias and death after an acute myocardial infarction. ${ }^{82}$

Magnesium likely predisposes to sudden cardiac death through several mechanisms. First, magnesium deficiency sensitises the myocardium to toxic effects of various drugs as well as to hypoxia. Therefore, magnesium supplementation may have significant cardioprotective effects. Second, magnesium activates the Na-K-ATPase, which may be inhibited by non-glucose fuels such as lactate and free fatty acid in the setting of ischaemia. Third, deficiency in magnesium may also lead to chronic electrical instability of the myocardium by affecting the sodium and calcium flow into the cells. ${ }^{83}$ A fourth potential mechanism is via the effect of hypomagnesaemia on vascular tone. In in vitro experiments, extracellular magnesium ions have been found to exert a profound beneficial influence on the contractility and reactivities of the arteries, arterioles and veins from a number of regional vasculatures and in several mammalian species, including humans. Hypomagnesaemia has also been observed to increase the contractile activity of a variety of neurohumoral substances and to potentiate vasospasm, likely by controlling the entry and distribution of calcium ions into the cells. Coronary vasospasm has thus been suggested as a possible mechanism of sudden cardiac death. ${ }^{84}$ Other experiments have taken isolated coronary arteries from dogs and exposed them to different concentrations of magnesium in the medium. High concentrations of magnesium were found to decrease the basal tension of the coronary arteries, whereas sudden withdrawal of magnesium increased the contractile function of both small and large coronary arteries. ${ }^{85}$ Similarly, Altura also found that lowering the magnesium contents around perfused arterioles can lead to spontaneous vasoconstriction as well as increased arteriolar resistance, tissue ischaemia and reduced venous outflow. Lastly, the concentration of circulating vasoconstrictor hormones, such as angiotensin, serotonin and acetylcholine, are increased when extracellular magnesium is lower than normal. ${ }^{86}$ It is possible that hypomagnesaemia produces progressive vasoconstriction and vasospasm, which then leads to ischaemia, giving rise to sudden cardiac death overtime.

Ways to supplement magnesium as a possible method to reduce sudden cardiac death include changing dietary habits to include magnesium-rich foods, adding magnesium to community water supplies, fortifying foods with magnesium as well as oral supplementation. ${ }^{82}$ More prospective, large-scale studies are needed to study the effect of magnesium supplementation as a means of primary prevention for sudden cardiac death.

\section{ATHEROSCLEROSIS}

Magnesium deficiency has been shown to play a role in lipoprotein metabolism and may be contributing to atherosclerosis as a cardiovascular risk factor. Endothelial cells cultured in low magnesium have been found to activate nuclear factor-kappa beta, which may in turn trigger the downstream cytokine network. Low magnesium levels in culture also increases the endothelial cell secretion of RANTES (regulated on activation, normal T cell expressed and secreted), interleukin 8 and platelet-derived growth factor-BB. All play an important role in atherogenesis. Additionally, endothelial cells when exposed to low magnesium increase the secretion of matrix metalloprotease- 2 and matrix metalloprotease-9 and their inhibitor, tissue inhibitor of metalloproteinases (TIMP-2). All of these pathways lead to endothelial dysfunction by promoting the expression 
of inflammatory cytokines in a state of magnesium deficiency. ${ }^{87}$

In rats fed a short-term magnesium-deficient diet, there is a reduction in the serum magnesium level, sphingomyelin level, phosphatidylcholine, high-density lipoprotein (HDL) cholesterol and the phosphatidylcholine:cholesterol ratio, concomitant with decreases in tissue levels of glutathione, leakage of cardiac creatine kinase (CK) and lactic dehydrogenase (LDH), as well as activation of nitric oxide synthetase (e-NOS and n-NOS) in all chambers of the heart. In addition, the changes in these parameters are dose dependent on the degree of magnesium deficiency, and they can lead to oxidative stress. Reductions in glutathione content as well as activation of e-NOS and n-NOS in various chambers of the heart have been hypothesised to produce early cardiac damage characterised by leakage of CK and LDH. Additionally, rats exposed to low dietary magnesium had de novo synthesis of ceramide, which was attenuated by inhibition of sphingomyelinase and serine palmitoyl CoA transferase. Hence, the activation of the sphingomyelin-ceramide pathway in a state of magnesium deficiency may also play a role in the pathogenesis of atherosclerosis. ${ }^{88}$ Low magnesium concentrations may also reversibly inhibit endothelial proliferation and alter endothelial migration via significant downregulation of CDC25B and an upregulation of interleukin-1 (IL-1), vascular cell adhesion molecule-1 and plasminogen activator inhibitor-1 after magnesium deficiency leading to a pro-atherosclerotic state. ${ }^{89}$

In one study, the effects of thiamine, magnesium and sulfate salts on the growth, thiamine levels and serum lipid level were tested in rats. Deficiency of both magnesium and sulfate salts in thiamine-supplemented groups decreased body weight gain and liver thiamine content, but elevated serum triglycerides. ${ }^{90}$ Animals given cyclophosphamide or methotrexate also had greater cardiac damage while on a low magnesium diet via its effect on blood lipid levels and atherogenesis. ${ }^{91}$ In humans, longterm magnesium deficiency has been found to lower serum magnesium levels and increase levels of lipids as well as serum glucose. In young, apparently healthy athletes, persistent magnesium deficiency as a result of strenuous physical activity was found to correlate with long-term increases in cholesterol, triglycerides and blood sugar. ${ }^{92}$ These studies suggest that magnesium supplementation may be beneficial as treatment for the primary prevention of atherosclerosis.

\section{CORONARY VASOSPASM}

Multiple studies have suggested a link between magnesium deficiency and coronary artery spasm. Magnesium controls the movement of calcium into smooth muscle cells, leading to smooth muscle contraction. In dogs, coronary arteries incubated in low magnesium solutions are predisposed to vasospasm. ${ }^{85}$ Additionally, low magnesium solution can significantly increase the potential for contractile responses of both small and large arteries to norepinephrine. ${ }^{85}$ Experiments of intact $\operatorname{dogs}^{93}$ and isolated coronary arteries of pigs also showed similar results. ${ }^{94}$ Low magnesium levels have been associated with variant angina in humans, and measurement of erythrocyte magnesium content is useful to determine how easily vasospasm may occur. ${ }^{95}$ Guo et al also evaluated the intracellular and extracellular magnesium status in 12 women with variant angina and found that the 24-hour magnesium retention rate and intracellular concentrations of magnesium in erythrocytes correlated well with the activity of variant angina. ${ }^{96}$ Teragawa $e t$ al demonstrated that magnesium infusion can produce non-site-specific basal coronary dilatation and suppresses acetylcholine-induced coronary spasm in patients with vasospastic angina. Magnesium infusion was also effective in reducing the severity of chest pain and ST-segment deviations during coronary spasm. After the magnesium infusion, the per cent change in the diameter of the spastic segments improved from $-62.8 \pm 2.6 \%$ to $-43.7 \pm 4.7 \%$ during coronary spasm. ${ }^{97}$ These studies suggest that magnesium may be beneficial for symptom control in patients with variant angina.

\section{OXIDATIVE STRESS AND MYOCARDIAL INJURY}

Evidence suggests that magnesium deficiency plays a role in myocardial infarction via increased oxidative stress. Magnesium deficiency has been associated with the production of reactive oxygen species, cytokines, as well as vascular compromise in vivo. ${ }^{98}$ Magnesium deficiency has also been shown to produce myocardial lesions in different animal models. In rats fed a diet deficient in magnesium, there is a significant lowering of superoxide dismutase and catalase in the rat heart, leading to depressed antioxidant defence in the heart and increased myocardial susceptibility to oxidative injury. ${ }^{99}$ Hans et al also demonstrated that magnesium deficiency is associated with increased oxidative stress through reductions in plasma antioxidants and increased lipid peroxidation, suggesting that the increased oxidative stress may be due to increased susceptibility of body organs to free radical injury. ${ }^{100}$ In Syrian hamsters placed on a magnesium-deficient diet, oxidation (isoprenaline)-induced injury was dramatically increased in magnesium-deficient rats. ${ }^{101}$ This finding suggests that magnesium deficiency increases the susceptibility of the cardiovascular system to oxidative damage. In humans, similar findings were reported. Kharb and Singh estimated serum malonaldehyde (MDA), magnesium, vitamin $\mathrm{E}$ and total glutathione levels (GSH) in 22 patients with acute myocardial infarction and 15 healthy controls. Low levels of magnesium, GSH, vitamin E and elevated levels of MDA were observed in patients with acute myocardial infarction. The findings suggest that magnesium deficiency can potentiate oxidative injury in post-ischaemic myocardium. ${ }^{102}$

Patients with acute myocardial infarction also tend to have lower magnesium content, particularly in the early hours after infarction. Urdal et al studied mononuclear 
cell magnesium and retention of magnesium after intravenous loading in patients with acute myocardial infarction compared with healthy volunteers. The study found that mononuclear cell magnesium concentrations before magnesium retention test were slightly higher in patients with acute myocardial infarction compared with healthy volunteers indicting no magnesium depletion in the acute myocardial infarction group. However, when magnesium retention test was performed 4-11 days after admission in the subjects with acute myocardial infarction, the retention of magnesium was $45 \pm 23 \%$ of the $30 \mathrm{mmol}$ given intravenously (retention of more than $20 \%$ generally represents magnesium deficiency). It is unclear what caused the increased retention of magnesium during the acute phase of myocardial infarction, but it may be due to increased concentrations of circulating catecholamines during the early hours of myocardial infarction. ${ }^{103}$ Rasmussen et al also found that patients with ischaemic heart disease both with and without acute myocardial infarction retained significantly more magnesium than did the control group of healthy volunteers. The increase in magnesium retention points to a state of magnesium deficiency in patients with ischaemic heart disease. Unsurprisingly, when the patients with ischaemic heart disease were subgrouped according to long-term diuretic treatment, the patients receiving long-term diuretic treatment had a 39\% retention of magnesium $(11.6 \mathrm{mmol} / \mathrm{L}(28.2 \mathrm{mg} / \mathrm{dL}))$ compared with a $29 \%$ retention $(8.7 \mathrm{mmol} / \mathrm{L}(21.1 \mathrm{mg} / \mathrm{dL}))$. This study indicates that patients with ischaemic heart disease may be severely magnesium deficient and that long-term diuretic treatment may contribute to this deficiency. ${ }^{104}$ The beneficial effect of intravenous magnesium treatment in acute myocardial infarction has also been demonstrated in regards to reducing both mortality and early cardiac insufficiency. Besides antiarrhythmic and vasodilatator effects, magnesium also seems to protect cardiac cells against the harmful effects of ischaemia. ${ }^{70}$

\section{THROMBOSIS}

In both animals and human models, magnesium deficiency has been linked to a prothrombotic state. In an uncontrolled study in 1954, Parsons et al found that patients with angina or myocardial infarction had a reduced death rate, from $30 \%$ to $1 \%$, if they were treated with magnesium sulfate intramuscularly. The improvement was thought to be secondary to favourable effects in reducing the inhibition of plasmin, an enzyme that plays an essential role in fibrinolysis and responsible for the degradation of fibrin clots. ${ }^{105} \mathrm{~A}$ more recent study in 1986 demonstrated that bleeding time increased with magnesium infusion in patients with acute myocardial infarction. ${ }^{106}$ Magnesium has been shown to inhibit ADP-induced platelet aggregation. ${ }^{107}$ In patients with pre-eclampsia, treatment with magnesium infusion has been shown to reduce certain clotting factors. ${ }^{108}$ In a 1989 paper, Paolisso et al found that magnesium administration can reduce platelet hypercoagulability in patients with non-insulin-dependent diabetes. ${ }^{109}$ Shecter also found that low intracellular magnesium levels promote platelet-dependent thrombosis in patients with coronary artery disease by exposing porcine aortic media to their flowing un-anticoagulated venous blood for $5 \mathrm{~min}$ by using an ex vivo perfusion chamber. ${ }^{110}$ These studies suggest that magnesium may play a role in thrombosis and supplementation with magnesium may be beneficial in certain population of patients.

\section{MAGNESIUM AND MITRAL VALVE PROLAPSE}

The mechanism of mitral valve prolapse has not been fully elucidated. However, magnesium deficiency has been proposed to be related to mitral valve prolapse syndrome. In a study comparing 49 subjects with mitral valve prolapse to age-matched and gender-matched subjects without mitral valve prolapse, both groups were found to have similar serum magnesium levels. However, subjects with mitral valve prolapse had lower magnesium levels in the lysate of their lymphocytes. The results suggest that lymphocyte magnesium deficiency may play a role in mitral valve prolapse. ${ }^{111}$ In a separate study by Licholdziejewska et al, serum magnesium levels in 141 subjects with heavily symptomatic mitral valve prolapse and 40 healthy subjects were compared. The group found that many patients with heavily symptomatic mitral valve prolapse have low serum magnesium, and magnesium supplementation leads to improvement in most symptoms such as chest pain, dyspnoea, weakness, palpitations and anxiety along with a decrease in catecholamine excretion. ${ }^{112}$ Further studies are needed to further elucidate the relationship between magnesium deficiency and mitral valve prolapse syndrome.

\section{DIABETES AND GLYCAEMIC CONTROL}

Magnesium deficiency has also been implicated in the pathogenesis of diabetes and poor glycaemic control. In animal models, magnesium deficiency as well as excess sucrose intake has been shown to be associated with the generation of reactive oxygen species. When male Wistar rats were divided into groups fed control, low-magnesium, high-sucrose and low-magnesium high-sucrose diet for a period of 3 months, the rats fed high sucrose and low magnesium diet were found to have significantly higher levels of lipid peroxidation in the plasma and liver tissue; however, the same effect was not observed in the other groups. These findings suggest that a diet low in magnesium and high in sucrose causes oxidative stress in rats, as reflected by increased lipid peroxidation and reduced antioxidant potential. ${ }^{113}$ In humans, randomised double-blind placebo-controlled trials have been done to study the effect of magnesium deficiency in diabetic patients. In a study conducted by Simental-Media et al, 62 men and non-pregnant women with a diagnosis of pre-diabetes and hypomagnesaemia were enrolled in the double-blind, placebo-controlled trial to receive either 
magnesium supplementation or placebo. At the end of the trial, subjects receiving magnesium supplementation were found to have higher levels of serum magnesium, as well as lower levels of high-sensitivity $\mathrm{C}$ reactive protein. ${ }^{114}$ In a separate randomised controlled trial, Guerrero-Romero et al showed that supplementation of oral magnesium in subjects with pre-diabetes and hypomagnesaemia improved glycaemic control. At the end of the follow-up period, subjects in the treatment group had significantly lower fasting and post-load glucose, homeostatic model assessment for insulin resistance indices and triglycerides, whereas HDL cholesterol and serum magnesium levels were significantly increased in those receiving magnesium supplementation. Remarkably, a total of $50.8 \%$ of those in the magnesium treatment group improved their glycaemic level compared with only $7 \%$ in the placebo group. ${ }^{115}$

\section{STROKE}

Hypomagnesaemia has also been found to be a risk factor for cerebrovascular events and complications. Szabo et al found that a slight decrease in extracellular magnesium from 1.2 to $0.8 \mathrm{mM}$ resulted in sustained relaxation when the endothelium was intact; however, when the endothelium was interrupted, the slight reduction in magnesium resulted in elevation of vascular tone. These results suggested that magnesium modules human cerebra-arterial tone through an endothelium-derived relaxing factor rather than by altering smooth muscle tone directly, and magnesium deficiency appears to drive endothelial dysfunction and hence atherosclerosis. ${ }^{116}$ Amighi et al investigated the prognostic impact of magnesium serum levels with respect to the occurrence of neurological events in patients with advanced atherosclerosis in 323 patients with symptomatic peripheral artery disease and intermittent claudication. Compared with patients in the highest tertile of magnesium serum levels $(>0.84 \mathrm{mmol} / \mathrm{L})$, patients with magnesium serum values $<0.76 \mathrm{mmol} / \mathrm{L}$ (lowest tertile) exhibited a 3.29-fold increased adjusted risk (95\% CI 1.34 to $7.90 ; \mathrm{p}=0.009$ ) for neurological events. However, patients with magnesium serum values of $0.76 \mathrm{mmol} / \mathrm{L}$ to $0.84 \mathrm{mmol} / \mathrm{L}$ (middle tertile) had no increased risk (adjusted HR 1.10; 95\% CI 0.35 to 3.33; $\mathrm{p}=0.88$ ). Hence, low serum magnesium levels appear to correlate with an increased risk for neurological events, defined as ischaemic stroke and/or carotid revascularisation. ${ }^{117}$ In a different study involving 40 patients with acute ischaemic strokes, low serum magnesium concentration was found to correlate with the intensity of neurological deficit at 48 hours after the onset of ischaemic stroke, as measured by the National Institute of Health Stroke Scale. Severity of paresis was also higher in patients with low serum magnesium levels. ${ }^{118}$ In summary, these studies seem to suggest that magnesium plays an important role in the pathogenesis of acute ischaemic stroke. However, more studies are necessary to further elucidate the mechanism by which magnesium exerts these effects in the cerebral-vascular system.

\section{CONCLUSION}

Magnesium plays an important role in cardiovascular health. It is instrumental for the proper maintenance of cellular membrane potential, functioning of the mitochondria and plays a key role in the body's antioxidative pathways. As a result, magnesium deficiency can lead to serious morbidity and mortality, and has been implicated in multiple cardiovascular diseases such as hypertension, cardiomyopathy, cardiac arrhythmia, atherosclerosis, dyslipidaemia and diabetes. Unfortunately, the western diet is often low in magnesium due to the refining and processing of foods, and hypomagnesaemia is often underdiagnosed in hospitalised patients. Studies have suggested that prompt diagnosis and timely supplementation of magnesium may be beneficial in patients with certain cardiac conditions. However, more prospective, randomised controlled trials are needed to be able to further elucidate the value of magnesium as a therapy to prevent or reverse some of the aforementioned cardiovascular conditions.

Contributors All authors contributed to the final manuscript.

Funding The authors have not declared a specific grant for this research from any funding agency in the public, commercial or not-for-profit sectors.

Competing interests JJD is the author of The Salt Fix and operates the website thesaltfix.com.

Patient consent Not required.

Provenance and peer review Not commissioned; internally peer reviewed.

Open Access This is an Open Access article distributed in accordance with the Creative Commons Attribution Non Commercial (CC BY-NC 4.0) license, which permits others to distribute, remix, adapt, build upon this work non-commercially, and license their derivative works on different terms, provided the original work is properly cited and the use is non-commercial. See: http://creativecommons.org/ licenses/by-nc/4.0/

(c) Article author(s) (or their employer(s) unless otherwise stated in the text of the article) 2018. All rights reserved. No commercial use is permitted unless otherwise expressly granted.

\section{REFERENCES}

1. National Institutes of Health. Magnesium. https://ods.od.nih.gov/ FactSheets/magnesium/.

2. Volpe SL. Magnesium. In: Erdman JW, Macdonald IA, Zeisel SH eds. Present knowledge in nutrition. 10th ed. Ames, lowa: John Wiley \& Sons, 2012:459-74.

3. Mazur A, Maier JA, Rock E, et al. Magnesium and the inflammatory response: potential physiopathological implications. Arch Biochem Biophys 2007;458:48-56.

4. Whang R, Ryder KW. Frequency of hypomagnesemia and hypermagnesemia. Requested vs routine. JAMA 1990;263:3063-4.

5. Ryzen E, Elkayam U, Rude RK. Low blood mononuclear cell magnesium in intensive cardiac care unit patients. Am Heart $J$ 1986;111:475-80.

6. Elin RJ. Assessment of magnesium status. Magnes Res 2010;23:194-8.

7. Ryzen E, Elbaum N, Singer FR, et al. Parenteral magnesium tolerance testing in the evaluation of magnesium deficiency. Magnesium 1985;4:137-47.

8. DiNicolantonio JJ, O'Keefe JH, Wilson W. Correction: Subclinical magnesium deficiency: a principal driver of cardiovascular disease and a public health crisis. Open Heart 2018;5.

9. Reinhart RA. Magnesium metabolism. A review with special reference to the relationship between intracellular content and serum levels. Arch Intern Med 1988;148:2415-20.

10. Ryan MF, Ryan MP. Lymphocyte electrolyte alterations during magnesium deficiency in the rat. Irish J Med Sci 1979;148:pp108-9. 
11. Elin RJ. Status of the determination of magnesium in mononuclear blood cells in humans. Magnesium 1988;7:1988300-5.

12. Lim P, Jacob E. Magnesium deficiency in patients on long-term diuretic therapy for heart failure. Br Med J 1972;3:620-2.

13. Purvis JR, Movahed A. Magnesium disorders and cardiovascular diseases. Clin Cardiol 1992;15:556-68.

14. Fischer PW, Giroux A. Effects of dietary magnesium on sodium-potassium pump action in the heart of rats. J Nutr 1987;117:2091-5.

15. Madden JA, Willems WJ, Smith GA, et al. Sodium kinetics and membrane potential in aorta of magnesium-deficient rats. Magnesium 1984;3:73-80.

16. Sheehan JP, Seelig MS. Interactions of magnesium and potassium in the pathogenesis of cardiovascular disease. Magnesium 1984;3:301-14.

17. Weglicki WB, Phillips TM. Pathobiology of magnesium deficiency: a cytokine/neurogenic inflammation hypothesis. Am J Physiol 1992;263:R734-R737.

18. Marier JR. Magnesium content of the food supply in the modernday world. Magnesium 1986;5:1-8.

19. Lichton IJ. Dietary intake levels and requirements of $\mathrm{Mg}$ and Ca for different segments of the U.S. population. Magnesium 1989;8:117-23.

20. Catling LA, Abubakar I, Lake IR, et al. A systematic review of analytical observational studies investigating the association between cardiovascular disease and drinking water hardness. $J$ Water Health 2008;6:433-42.

21. Sharper AG, Water S. Heart attacks, and stroke. JAMA 1974;7:130-1.

22. Anderson TW, Neri LC, Schreiber GB, et al. Letter: Ischemic heart disease, water hardness and myocardial magnesium. Can Med Assoc J 1975;113:199-203.

23. Abu-Zeid HA. The water factor and mortality from ischemic heart disease: a review and possible explanations for inconsistent findings with additional data from Manitoba. Arch Environ Health 1979;34:328-36.

24. Neri LC, Hewitt D, Mandel JS. Risk of sudden death in soft water areas. Am J Epidemiol 1971;94:101-4.

25. Lindeman RD, Assenzo JR. Correlations between water hardness and cardiovascular deaths in oklahoma counties. Am J Public Health Nations Health 1964;54:1071-7.

26. Allwright SP, Coulson A, Detels R, et al. Mortality and waterhardness in three matched communities in Los Angeles. Lancet 1974;2:860-4.

27. Mulcahy R. The influence of water hardness and rainfall on the incidence of cardiovascular and cerebrovascular mortality in Ireland. J Ir Med Assoc 1964:55:196417-8.

28. Singh RB, Rastogi SS, Mehta PJ, et al. Magnesium metabolism in essential hypertension. Acta Cardiol 1989;44:313-22.

29. Altura BM, Altura BT. Interactions of Mg and $\mathrm{K}$ on blood vesselsaspects in view of hypertension. Review of present status and new findings. Magnesium;3:1984175-94.

30. Ryan MP, Brady HR. The role of magnesium in the prevention and control of hypertension. Ann Clin Res 1984;16:81-8.

31. Shibutani Y, Sakamoto K, Katsuno S, et al. Serum and erythrocyte magnesium levels in junior high school students: relation to blood pressure and a family history of hypertension. Magnesium 1988;7:188-94.

32. Rylander R, Arnaud MJ. Mineral water intake reduces blood pressure among subjects with low urinary magnesium and calcium levels. BMC Public Health 2004:4:56

33. Zhang X, Li Y, Del Gobbo LC, et al. Effects of magnesium supplementation on blood pressure: a meta-analysis of randomized double-blind placebo-controlled trials. Hypertension 2016;68:324-33.

34. Kass L, Weekes J, Carpenter L. Effect of magnesium supplementation on blood pressure: a meta-analysis. Eur J Clin Nutr 2012;66:411-8.

35. Hattori K, Saito K, Sano H, et al. Intracellular magnesium deficiency and effect of oral magnesium on blood pressure and red cell sodium transport in diuretic-treated hypertensive patients. Jpn Circ J 1988;52:1249-56.

36. Rosanoff A, Plesset MR. Oral magnesium supplements decrease high blood pressure (SBP>155 mmHg) in hypertensive subjects on anti-hypertensive medications: a targeted meta-analysis. Magnes Res 2013;26:93-9.

37. Ahmad A, Bloom S. Sodium pump and calcium channel modulation of Mg-deficiency cardiomyopathy. Am J Cardiovasc Pathol 1989;2:277-83

38. Freedman AM, Atrakchi AH, Cassidy MM, et al. Magnesium deficiency-induced cardiomyopathy: protection by vitamin E. Biochem Biophys Res Commun 1990;170:1102-6.
39. Herbaczynska-Cedro K, Gajkowska B. Effect of magnesium on myocardial damage induced by epinephrine. Ultrastructural and cytochemical study. Cardioscience 1992;3:197-203.

40. Giles TD, Iteld BJ, Rives KL. The cardiomyopathy of hypoparathyroidism. Chest 1981;79:225-9.

41. Seelig MS. Magnesium deficiency in the pathogenesis of disease: early roots of cardiovasculac skeletal, and renal abnormalities, 1980

42. Valiathan MS, Kartha CC, Panday VK, et al. A geochemical basis for endomyocardial fibrosis. Cardiovasc Res 1986;20:679-82.

43. Valiathan SM, Kartha CC. Endomyocardial fibrosis - the possible connexion with myocardial levels of magnesium and cerium. Int $J$ Cardiol 1990;28:1-5.

44. Altura BM, Altura BT. Biochemistry and pathophysiology of congestive heart failure: is there a role for magnesium? Magnesium 1986;5:134-43.

45. Dyckner T, Wester PO. Magnesium deficiency in congestive heart failure. Acta Pharmacol Toxicol 1984;54:119-23.

46. Dyckner T, Wester PO. Renal excretion of electrolytes in patients on long-term diuretic therapy for arterial hypertension and/or congestive heart failure. Acta Med Scand 1985;218:443-8.

47. Ryan MP, Ryan MF, Counihan TB. The effect of diuretics on lymphocyte magnesium and potassium. Acta Med Scand 1981;209:153-61.

48. Abraham AS. Diuretics and intracellular cations. Drugs 1986;31(Suppl 4):109-11.

49. Dyckner T, Wester PO. Intracellular magnesium loss after diuretic administration. Drugs 1984;28 Suppl 1:161-6.

50. Gottlieb SS. Importance of magnesium in congestive heart failure. Am J Cardiol 1989;63:G39-G42.

51. Packer M. Sudden unexpected death in patients with congestive heart failure: a second frontier. Circulation 1985;72:681-5.

52. Flink EB, Brick JE, Shane SR. Alterations of long-chain free fatty acid and magnesium concentrations in acute myocardial infarction. Arch Intern Med 1981;141:441-3.

53. Wester PO, Dyckner T. Intracellular electrolytes in cardiac failure. Acta Med Scand Suppl 1986;707:33-6.

54. Song EK, Kang SM. Micronutrient deficiency independently predicts adverse health outcomes in patients with heart failure. $J$ Cardiovasc Nurs 2017;32:47-53.

55. Storm W, Zimmerman JJ. Magnesium deficiency and cardiogenic shock after cardiopulmonary bypass. Ann Thorac Surg 1997;64:572-7.

56. Gottlieb SS, Baruch L, Kukin ML, et al. Prognostic importance of the serum magnesium concentration in patients with congestive heart failure. J Am Coll Cardiol 1990;16:827-31.

57. Bashir Y, Sneddon JF, Staunton HA, et al. Effects of long-term oral magnesium chloride replacement in congestive heart failure secondary to coronary artery disease. Am J Cardio 1993; $72: 1156-62$

58. Ralston MA, Murnane MR, Kelley RE, et al. Magnesium content of serum, circulating mononuclear cells, skeletal muscle, and myocardium in congestive heart failure. Circulation 1989;80:573-80.

59. Cohen L, Laor A, Kitzes R. Prolonged Q-Tc interval and decreased lymphocyte magnesium in congestive heart failure. Magnesium 1984;3:164-8

60. Davis WH, Ziady F. The effect of oral magnesium chloride therapy on the QTC and QUc intervals of the electrocardiogram. S Afr Med $J$ 1978;53:591-3

61. Laban E, Charbon GA. Magnesium and cardiac arrhythmias: nutrient or drug? J Am Coll Nutr 1986;5:521-32.

62. Boyd JC, Bruns DE, DiMarco JP, et al. Relationship of potassium and magnesium concentrations in serum to cardiac arrhythmias. Clin Chem 1984;30:754-7.

63. Dyckner T, Wester PO. Potassium/magnesium depletion in patients with cardiovascular disease. Am J Med 1987:82:11-17.

64. Hollifield JW. Thiazide treatment of hypertension. Effects of thiazide diuretics on serum potassium, magnesium, and ventricular ectopy. Am J Med 1986;80:8-12.

65. Hollifield JW. Potassium and magnesium abnormalities: diuretics and arrhythmias in hypertension. Am J Med 1984;77:28-32.

66. Dyckner T, Wester PO. Relation between potassium, magnesium and cardiac arrhythmias. Acta Med Scand Suppl 1981;647:163-9.

67. Dyckner T, Wester PO. Ventricular extrasystoles and intracellular electrolytes before and after potassium and magnesium infusions in patients on diuretic treatment. Am Heart J 1979;97:12-18.

68. Cannon LA, Lloyd T. Magnesium levels in cardiac arrest victims: relation to successful resuscitation. Ann Emerg Med 1986;15:616. 190/639.

69. Ganga HV, Noyes A, White CM, et al. Magnesium adjunctive therapy in atrial arrhythmias. Pacing Clin Electrophysiol 2013;36:1308-18. 
70. Maurat JP, Kantelip JP, Anguenot T, et al. [Cardiovascular pathology and magnesium]. Therapie 1993;48:599-607.

71. Khan AM, Lubitz SA, Sullivan LM, et al. Low serum magnesium and the development of atrial fibrillation in the community: the Framingham Heart Study. Circulation 2013;127:33-8.

72. DeCarli C, Sprouse G, LaRosa JC. Serum magnesium levels in symptomatic atrial fibrillation and their relation to rhythm control by intravenous digoxin. Am J Cardiol 1986;57:956-9.

73. Lewis RV, Tregaskis B, McLay J, et al. Oral magnesium reduces ventricular ectopy in digitalised patients with chronic atrial fibrillation. Eur J Clin Pharmacol 1990;38:107-10.

74. Eray O, Akça S, Pekdemir M, et al. Magnesium efficacy in magnesium deficient and nondeficient patients with rapid ventricular response atrial fibrillation. Eur J Emerg Med 2000;7:287-90.

75. Cohen L, Kitzes R, Shnaider H. Multifocal atrial tachycardia responsive to parenteral magnesium. Magnes Res 1988;1:239-42.

76. Cohen L, Kitzes R. Magnesium sulfate and digitalis-toxic arrhythmias. JAMA 1983;249:2808-10.

77. Iseri LT. Role of magnesium in cardiac tachyarrhythmias. Am J Cardiol 1990;65:K47-K50.

78. Bean BL, Varghese PJ. Role of dietary magnesium deficiency in the pressor and arrhythmogenic response to epinephrine in the intact dog. Am Heart $J$ 1994;127:96-102.

79. Krasner BS, Girdwood R, Smith H. The effect of slow releasing oral magnesium chloride on the QTc interval of the electrocardiogram during open heart surgery. Can Anaesth Soc J 1981;28:329-33.

80. Raghu C, Peddeswara Rao P, Seshagiri Rao D. Protective effect of intravenous magnesium in acute myocardial infarction following thrombolytic therapy. Int J Cardiol 1999;71:209-15.

81. Papaceit J, Moral V, Recio J, et al. [Severe heart arrhythmia secondary to magnesium depletion. Torsade de pointes]. Rev Esp Anestesiol Reanim 1990;37:28-31.

82. Eisenberg MJ. Magnesium deficiency and sudden death. Am Heart J 1992;124:544-9.

83. Singh RB, Singh VP, Cameron EA. Magnesium in atherosclerotic cardiovascular disease and sudden death. Acta Cardiol 1981;36:411-29.

84. Altura BM, Altura BT, Carella A, et al. Hypomagnesemia and vasoconstriction: possible relationship to etiology of sudden death ischemic heart disease and hypertensive vascular diseases. Artery 1981;9:212-31.

85. Turlapaty PD, Altura BM. Magnesium deficiency produces spasms of coronary arteries: relationship to etiology of sudden death ischemic heart disease. Science 1980;208:198-200.

86. Altura BM. Sudden-death ischemic heart disease and dietary magnesium intake: is the target site coronary vascular smooth muscle? Med Hypotheses 1979;5:843-8.

87. Ferrè $\mathrm{S}$, Baldoli $\mathrm{E}$, Leidi $\mathrm{M}$, et al. Magnesium deficiency promotes a pro-atherogenic phenotype in cultured human endothelial cells via activation of NFkB. Biochim Biophys Acta 2010;1802:952-8.

88. Shah NC, Liu JP, lqbal J, et al. Mg deficiency results in modulation of serum lipids, glutathione, and NO synthase isozyme activation in cardiovascular tissues: relevance to de novo synthesis of ceramide serum Mg and atherogenesis. Int J Clin Exp Med 2011;4:103-18.

89. Maier JA, Malpuech-Brugère $C$, Zimowska W, et al. Low magnesium promotes endothelial cell dysfunction: implications for atherosclerosis, inflammation and thrombosis. Biochim Biophys Acta 2004;1689:13-21.

90. el-Hindi HM, Amer HA. Effect of thiamine, magnesium, and sulfate salts on growth, thiamine levels, and serum lipid constituents in rats. J Nutr Sci Vitaminol 1989;35:505-10.

91. Altura BT, Brust M, Bloom S, et al. Magnesium dietary intake modulates blood lipid levels and atherogenesis. Proc Natl Acad Sci U S A 1990;87:1840-4.

92. Stendig-Lindberg G. Sudden death of athletes: is it due to longterm changes in serum magnesium, lipids and blood sugar? $J$ Basic Clin Physiol Pharmacol 1992;3:153-64.

93. Chadda KD, Schultz NA. Magnesium deficiency and coronary vasospasm: role in sudden cardiac death. Magnesium 1982;1:86-94.

94. Yanagisawa-Miwa A, Ito $\mathrm{H}$, Sugimoto $\mathrm{T}$. Effects of insulin on vasoconstriction induced by thromboxane $\mathrm{A} 2$ in porcine coronary artery. Circulation 1990;81:1654-9.
95. Tanabe K, Noda K, Kamegai M, et al. Variant angina due to deficiency of intracellular magnesium. Clin Cardiol 1990;13:663-5.

96. Guo H, Cheng J, Lee JD, et al. Relationship between the degree of intracellular magnesium deficiency and the frequency of chest pain in women with variant angina. Herz 2004;29:299-303.

97. Teragawa $\mathrm{H}$, Kato $\mathrm{M}$, Yamagata $\mathrm{T}$, et al. The preventive effect of magnesium on coronary spasm in patients with vasospastic angina. Chest 2000;118:1690-5.

98. Wiles ME, Wagner TL, Weglicki WB. Effect of acute magnesium deficiency $(\mathrm{MgD})$ on aortic endothelial cell $(\mathrm{EC})$ oxidant production. Life Sci 1997;60:221-36.

99. Kumar BP, Shivakumar K. Depressed antioxidant defense in rat heart in experimental magnesium deficiency. Implications for the pathogenesis of myocardial lesions. Biol Trace Elem Res 1997:60:139-44.

100. Hans CP, Chaudhary DP, Bansal DD. Magnesium deficiency increases oxidative stress in rats. Indian J Exp Biol 2002;40:1275-9.

101. Freedman AM, Cassidy MM, Weglicki WB. Magnesium-deficient myocardium demonstrates an increased susceptibility to an in vivo oxidative stress. Magnes Res 1991;4:185-9.

102. Kharb S, Singh V. Magnesium deficiency potentiates free radical production associated with myocardial infarction. $J$ Assoc Physicians India 2000;48:484-5.

103. Urdal P, Landmark K, Basmo GM. Mononuclear cell magnesium and retention of magnesium after intravenous loading in patients with acute myocardial infarction. Scand J Clin Lab Invest 1992;52:763-6.

104. Rasmussen HS, McNair P, Gøransson L, et al. Magnesium deficiency in patients with ischemic heart disease with and without acute myocardial infarction uncovered by an intravenous loading test. Arch Intern Med 1988:148:329-32.

105. Parsons RS, Butler T, Sellars EP. The treatment of coronary artery disease with parenteral magnesium sulphate. Med Proc 1959:487.

106. Jeppesen BB. Magnesium status in patients with acute myocardial infarction: a pilot study. Magnesium 1986;5:95-100.

107. Cantón R, Manzanares J, Alvarez E, et al. In vitro and in vivo antiaggregant effects of magnesium halogenates. Thromb Haemost 1987;58:957-9.

108. Lox CD, Dorsett MM, Hampton RM. Observations on clotting activity during pre-eclampsia. Clin Exp Hypertens B 1983;2:179-90.

109. Paolisso G, Tirelli A, Coppola L, et al. Magnesium administration reduces platelet hyperaggregability in NIDDM. Diabetes Care 1989;12:167-8.

110. Shechter M. The role of magnesium as antithrombotic therapy. Wien Med Wochenschr 2000;150:343-7.

111. Kitliński M, Stepniewski M, Nessler J, et al. Is magnesium deficit in lymphocytes a part of the mitral valve prolapse syndrome? Magnes Res 2004;17:39-45.

112. Lichodziejewska B, Kłoś J, Rezler J, et al. Clinical symptoms of mitral valve prolapse are related to hypomagnesemia and attenuated by magnesium supplementation. Am J Cardiol 1997;79:768-72.

113. Chaudhary DP, Boparai RK, Bansal DD. Implications of oxidative stress in high sucrose low magnesium diet fed rats. Eur $J$ Nutr 2007:46:383-90.

114. Simental-Mendía LE, Rodríguez-Morán M, Guerrero-Romero F. Oral magnesium supplementation decreases C-reactive protein levels in subjects with prediabetes and hypomagnesemia: a clinical randomized double-blind placebo-controlled trial. Arch Med Res 2014;45:325-30.

115. Guerrero-Romero F, Simental-Mendía LE, Hernández-Ronquillo $\mathrm{G}$, et al. Oral magnesium supplementation improves glycaemic status in subjects with prediabetes and hypomagnesaemia: a double-blind placebo-controlled randomized trial. Diabetes Metab 2015;41:202-7.

116. Szabó C, Hardebo JE, Salford LG. Role of endothelium in the responses of human intracranial arteries to a slight reduction of extracellular magnesium. Exp Physiol 1992;77:209-11.

117. Amighi J, Sabeti S, Schlager O, et al. Low serum magnesium predicts neurological events in patients with advanced atherosclerosis. Stroke 2004;35:22-7.

118. Cojocaru IM, Cojocaru M, Burcin C, et al. Serum magnesium in patients with acute ischemic stroke. Rom J Intern Med 2007:45:269-73. 